Article

\title{
Exploitation of Kiwi Juice Pomace for the Recovery of Natural Antioxidants through Microwave-Assisted Extraction
}

\author{
Katya Carbone $^{1, * \mathbb{D}}$, Tiziana Amoriello ${ }^{2} \mathbb{D}$ and Rosamaria Iadecola ${ }^{1}$ \\ 1 Consiglio per la ricerca in agricoltura e l'analisi dell'economia agraria, Research Centre for Olive, \\ Fruit and Citrus Crops, Via di Fioranello 52, 00134 Rome, Italy; r.iadecola@gmail.com \\ 2 Consiglio per la ricerca in agricoltura e l'analisi dell'economia agraria, \\ Research Centre for Food and Nutrition, Via Ardeatina 546, 00178 Rome, Italy; tiziana.amoriello@crea.gov.it \\ * Correspondence: katya.carbone@crea.gov.it
}

Received: 30 August 2020; Accepted: 23 September 2020; Published: 26 September 2020

check for updates

\begin{abstract}
In a completely green approach to the exploitation of kiwi juice pomace (KP), a microwaved-assisted extraction (MAE) process was performed to extract antioxidant compounds present in $\mathrm{KP}$, evaluating the influence of four independent process variables (temperature $(\mathrm{T})$, extraction time (E), solvent composition (C), and solid-to-solvent ratio (R)) on the response of total phenolic content (TPC). The optimal conditions for the green extraction of total polyphenols from KP were obtained using a three-level fractional factorial design under response surface methodology (RSM) coupled with desirability optimization, and a feed-forward multilayered perceptron artificial neural network (ANN) with a back-propagation algorithm. Data were analyzed by ANOVA and fitted to a second-order polynomial equation using the regression method. Results showed that $\mathrm{T}$ was the most influential factor, followed by R and C, whereas the extraction time (E) was not shown to have a significant linear effect on the extraction yield of total polyphenols (TPs). The optimal conditions based on both individual and combinations of all responses were found out $\left(\mathrm{T}: 75^{\circ} \mathrm{C}\right.$; E: 15 min; C: 50\% ethanol:water; R: 1:15), and under these conditions the obtained extract showed both a high bioactive compound content and a high antioxidant potential, pointing out how this by-product could become an inexpensive source of compounds with high added value. A very good agreement was observed between experimental and calculated extraction yields, thus supporting the use of these models to quantitatively describe the recovery of natural antioxidants from KP. Finally, the ANN model exhibited more accurate prediction and better generalization capabilities than the RSM model ( $\mathrm{R}^{2}$ : 0.90 and 0.99 , for RSM and ANN, respectively).
\end{abstract}

Keywords: kiwi juice pomace; polyphenols; surface response methodology; artificial neural network

\section{Introduction}

Kiwifruit is the edible berry of several species of woody vines in the genus Actinidia, which contains 76 species and about 125 known taxa worldwide [1]. It is native of north-central and eastern China and is now cultivated also in Europe (25.2\% of the world production) and Oceania (14\% of the world production). In terms of crop value, kiwifruit is the sixth most valuable fruit crop after citrus, apples, table grapes, peaches/nectarines, and pears [2]. The worldwide kiwifruit production has increased significantly in the last years from 2,511,732 tons in 2006 to about $4 \mathrm{M}$ tons in 2016 [3]. China is the top worldwide producer of kiwifruit, with an estimated annual production of more than 2 million tons, and Italy is the second largest producer worldwide and the leading crop producer in Europe with around 523,595 tons per year [3]. Despite the spreading of new varieties developed from different 
species, the most popular and internationally traded cultivar is the green-fleshed "Hayward" (Actinidia deliciosa), whose distinctive appearance and flavor are highly appreciated by consumers.

Kiwifruit can be considered a product with a high nutritional value due to its high level of vitamin $\mathrm{C}$ and to the presence of a large number of phytonutrients including carotenoids, lutein, phenolics, flavonoids and chlorophyll [4] that contribute to the total antiradical potential of the fruit and to its ability of limiting oxidative stress due to reactive oxygen species (ROS), making it a "functional food" [5]. By virtue of these characteristics, the kiwi is indicated as a food aid for specific health conditions and represents a commodity with great industrial potential. Kiwifruit is either consumed as raw fruit or processed into juice, jam, and wine. Kiwi pomace (KP), the press cake residue left after kiwifruit juice manufacture, is the primary by-product of the kiwi juice industry, accounting for about $20-40 \%$ of the whole fruit [6]. These materials are a burden on producers as the management of these food wastes is becoming extremely difficult. Despite this, fruit pomaces are an abundant source of valuable compounds [7]. KP has recently been investigated as a source of hydrocolloids and dietary fibers [6]. However, only few studies are currently available on the exploitation of kiwifruit by-products such as seeds or peels [8], while only one study has been reported on the bioactive value of kiwifruit bagasse (seeds and pulp residues from juice extraction; [9]).

One of the main critical issues to maximize the valorization of agro-food waste and by-products is to find a suitable separative/extractive technique able to ensure the highest recovery of phytochemicals. In fact, these compounds differ in their solubility, a parameter that influences the recovery yield, complicating their individual or targeted extraction [7].

Traditional methods for extracting phytochemicals are based on solid-liquid extraction techniques such as maceration, percolation, and Soxhlet extraction. However, these methods are time- and solvent-consuming, laborious, with high operational costs; moreover, the extraction yields obtained are usually poor. As a consequence, advanced methods are necessary to obtain acceptable results in terms of both yields and environmental sustainability.

Up to date, different innovative, nonconventional and green extraction techniques have been reported as alternatives to conventional methods for polyphenol extraction [10]. Among these new green extraction techniques, microwave-assisted extraction (MAE) has been reported to be an efficient, green and promising technique for the recovery of natural compounds from plant by-products [7,10]. The efficiency of a MAE process is related to the optimization of different critical operative parameters such as time, temperature, solvent choice, and solid-to-solvent ratio [10]. As a consequence, a rigorous approach based on chemometrics is necessary to model and optimize the extraction process. Response surface methodology (RSM) is a statistical tool successfully used to test process parameters and their interactive effects in order to design a mathematical model able to represent the process in its entirety. It outdoes the traditional, expensive and time-consuming one-variable-at-a-time approach, with all factors being simultaneously varied with a reduced number of assays.

Recently, as an alternative to conventional statistical methods, prediction techniques based on artificial intelligence have been proposed in the literature [11]. Among them, Artificial Neural Networks (ANNs) are mathematical techniques used in a wide range of biotechnological applications for nonlinear multivariate modelling that estimates the response variable without any assumption on the nature of the phenomenon and the relationships among variables. ANNs can use RSM experimental data to build an effective ANN model and literature data support models developed with RSM and ANNs based on the same design of experiment (DoE). These studies highlight how a neural network model can be successfully constructed using RSM experimental data, and the predictive capability of the ANN model can be better than that of the RSM [12,13].

To date, several attempts have been made to assess the value of RSM and ANNs to predict and simulate the recovery of phenolic compounds from plant materials [14]. However, to the best of our knowledge, there is no data about a comparative evaluation of these techniques concerning their prediction ability regarding phenolic compound recovery from kiwi pomace using a MAE process. 
In light of these considerations, the aim of the present study was to investigate the potentiality of MAE as a green extraction technique for the recovery of natural antioxidants from kiwi pomace. Moreover, we investigated the influence and combined effects of the main process parameters (temperature, extraction time, solvent composition, and solid-to-solvent ratio) on total polyphenol yield, and compared the efficiencies of predictive models generated with RSM and ANNs.

Finally, the phytochemical characterization of the optimized KP extract was carried out.

\section{Materials and Methods}

\subsection{Chemicals}

Authentic standards of gallic acid, catechin, vanillin, Folin-Ciocalteau reagent were purchased from Sigma-Aldrich (Milan, Italy), as well as 2,2'-azino-bis(3-ethylbenzthiazoline-6-sulphonic acid) (ABTS), potassium persulfate, and 2,2-diphenyl-1-picrylhydrazyl radical (DPPH). All other solvents and chemicals were of the highest commercial grade and were purchased from VWR (Milan, Italy). Pure water was prepared by a Milli-Q purification system (Millipore, Bedford, MA, USA).

\subsection{Plant Material and Juice Production}

Kiwifruits (Actinidia deliciosa, cv. "Hayward") were harvested at the commercial maturity stage from an orchard located in the production district of the Latium Region (Italy) and then ripened at $4{ }^{\circ} \mathrm{C}$ to reach an average firmness of $1 \mathrm{~kg} \mathrm{~cm}^{2}$, and a soluble solid content ranged between $14.4^{\circ}$ and $15.0^{\circ}$ Brix. Ten kilograms of fruits were sanitized with sodium hypochlorite $\left(100 \mathrm{mg} \mathrm{L}^{-1}\right)$ for $5 \mathrm{~min}$ at room temperature and rinsed with tap water, drained for $5 \mathrm{~min}$, hand-peeled, cut into pieces and homogenized in a Vitae Ju2000 juicer (Moulinex, Italy), and the resulting pomace (seeds and pulp residues) was freeze-dried. Drying has a dual role, in view of the use of this waste in other sectors (such as food or cosmeceutical). The first is to stabilize it, the second is to obtain phytoextracts titrated on a dry basis, regardless of the water content of the matrix that would affect the extraction in an uncontrolled way, especially when using a hydroalcoholic mixture as a solvent medium.

Prior to be extracted, KP was then grinded with a laboratory mill into a fine powder (sieve $0.5 \mathrm{~mm}$ ) and stored at $-80^{\circ} \mathrm{C}$ prior to further extraction experiments.

\subsection{Design of Experiments}

In this study, the experiments were established based on a three-level fractional factorial design with four independent process parameters (temperature, extraction time, solvent composition, and solid-to-solvent ratio), known to affect extraction yield and phytochemical contents [15]. The selection of the best combination of these parameters was based on the maximum value of total phenolic content (TPC) of the obtained extract.

The design included 27 runs; each run was replicated four times. Each factor was coded at three levels, $-1,0,+1$, whereas solvent composition ranged between 0 and $100 \%$ (ethanol:water; $w / w$ ); solid-to-solvent ratio between 10 and $30 \mathrm{~g} \mathrm{~mL}^{-1}$; temperature between 25 and $75{ }^{\circ} \mathrm{C}$; extraction time between 5 and $15 \mathrm{~min}$ (Table 1). In this context, the range of values of each factor was chosen based on both the literature data and preliminary experiments. 
Table 1. Fractional factorial design with coded and uncoded parameters of microwave-assisted extraction (MAE), and experimental and predicted response values (Total Phenolic Content, TPC) in the obtained extracts using response surface methodology (RSM) and artificial neural network (ANN).

\begin{tabular}{|c|c|c|c|c|c|c|c|c|c|c|c|}
\hline \multirow[b]{2}{*}{ Run } & \multicolumn{4}{|c|}{ Coded Factors } & \multicolumn{4}{|c|}{ Uncoded Factors } & \multicolumn{3}{|c|}{$\begin{array}{c}\text { TPC } \\
\left(\mathrm{mg} \mathrm{GAE}^{-1} \mathrm{dw}\right)^{\mathrm{a}} \\
\end{array}$} \\
\hline & $X_{1}$ & $X_{2}$ & $X_{3}$ & $X_{4}$ & $\begin{array}{c}\text { Solvent Composition, \% } \\
\left(\mathrm{X}_{1}\right)\end{array}$ & $\begin{array}{l}\text { Solid-to-Solvent Ratio } \\
\left(\mathrm{X}_{2}\right)\end{array}$ & $\begin{array}{c}\text { Temperature, }{ }^{\circ} \mathrm{C} \\
\left(\mathrm{X}_{3}\right)\end{array}$ & $\begin{array}{l}\text { Extraction Time, min } \\
\left(\mathrm{X}_{4}\right)\end{array}$ & Experimental & Predicted $_{\text {RSM }}$ & Predicted $_{\text {ANN }}$ \\
\hline 1 & -1 & -1 & -1 & -1 & 0 & 1:10 & 25 & 5 & $3.6 \pm 0.2 \mathrm{f}$ & 3.40 & 3.59 \\
\hline 2 & -1 & -1 & 0 & 0 & 0 & $1: 10$ & 50 & 10 & $2.40 \pm 0.06 \mathrm{~d}$ & 3.16 & 2.41 \\
\hline 3 & -1 & -1 & 1 & 1 & 0 & 1:10 & 75 & 15 & $4.87 \pm 0.02 \mathrm{k}$ & 4.13 & 4.90 \\
\hline 4 & -1 & 0 & -1 & 0 & 0 & $1: 20$ & 25 & 10 & $3.3 \pm 0.5 \mathrm{f}$ & 3.31 & 3.38 \\
\hline 5 & -1 & 0 & 0 & 1 & 0 & $1: 20$ & 50 & 15 & $3.40 \pm 0.08 \mathrm{f}$ & 3.21 & 3.39 \\
\hline 6 & -1 & 0 & 1 & -1 & 0 & $1: 20$ & 75 & 5 & $3.33 \pm 0.08 \mathrm{f}$ & 3.40 & 3.31 \\
\hline 7 & -1 & 1 & -1 & 1 & 0 & 1:30 & 25 & 15 & $3.49 \pm 0.04 \mathrm{f}$ & 3.77 & 3.40 \\
\hline 8 & -1 & 1 & 0 & -1 & 0 & $1: 30$ & 50 & 5 & $3.3 \pm 0.7 \mathrm{f}$ & 3.37 & 3.30 \\
\hline 9 & -1 & 1 & 1 & 0 & 0 & $1: 30$ & 75 & 10 & $3.1 \pm 0.1 \mathrm{f}$ & 3.13 & 3.09 \\
\hline 10 & 0 & -1 & -1 & 1 & 50 & $1: 10$ & 25 & 15 & $3.83 \pm 0.06 \mathrm{f}$ & 3.98 & 3.83 \\
\hline 11 & 0 & -1 & 0 & -1 & 50 & 1:10 & 50 & 5 & $4.25 \pm 0.02 \mathrm{~h}$ & 4.25 & 4.28 \\
\hline 12 & 0 & -1 & 1 & 0 & 50 & 1:10 & 75 & 10 & $4.57 \pm 0.02 \mathrm{i}$ & 4.90 & 4.53 \\
\hline 13 & 0 & 0 & -1 & -1 & 50 & $1: 20$ & 25 & 5 & $4.70 \pm 0.08 j$ & 4.32 & 4.63 \\
\hline 14 & 0 & 0 & 0 & 0 & 50 & $1: 20$ & 50 & 10 & $4.12 \pm 0.07 \mathrm{~g}$ & 3.90 & 4.07 \\
\hline 15 & 0 & 0 & 1 & 1 & 50 & $1: 20$ & 75 & 15 & $4.0 \pm 0.2 \mathrm{fg}$ & 4.70 & 4.00 \\
\hline 16 & 0 & 1 & -1 & 0 & 50 & $1: 30$ & 25 & 10 & $4.69 \pm 0.06 j$ & 4.37 & 4.79 \\
\hline 17 & 0 & 1 & 0 & 1 & 50 & $1: 30$ & 50 & 15 & $4.20 \pm 0.08 \mathrm{gh}$ & 4.10 & 4.27 \\
\hline 18 & 0 & 1 & 1 & -1 & 50 & $1: 30$ & 75 & 5 & $4.23 \pm 0.05 \mathrm{gh}$ & 4.10 & 4.24 \\
\hline 19 & 1 & -1 & -1 & 0 & 100 & 1:10 & 25 & 10 & $1.36 \pm 0.06 \mathrm{a}$ & 1.34 & 1.40 \\
\hline 20 & 1 & -1 & 0 & 1 & 100 & 1:10 & 50 & 15 & $2.01 \pm 0.03 \mathrm{c}$ & 1.95 & 2.01 \\
\hline 21 & 1 & -1 & 1 & -1 & 100 & 1:10 & 75 & 5 & $2.86 \pm 0.07 \mathrm{e}$ & 2.62 & 2.90 \\
\hline 22 & 1 & 0 & -1 & 1 & 100 & $1: 20$ & 25 & 15 & $1.5 \pm 0.1 \mathrm{a}$ & 1.45 & 1.56 \\
\hline 23 & 1 & 0 & 0 & -1 & 100 & $1: 20$ & 50 & 5 & $1.3 \pm 0.2 \mathrm{a}$ & 1.53 & 1.30 \\
\hline 24 & 1 & 0 & 1 & 0 & 100 & $1: 20$ & 75 & 10 & $2.06 \pm 0.07 \mathrm{c}$ & 2.00 & 2.09 \\
\hline 25 & 1 & 1 & -1 & -1 & 100 & $1: 30$ & 25 & 5 & $1.3 \pm 0.1 \mathrm{a}$ & 1.93 & 1.32 \\
\hline 26 & 1 & 1 & 0 & 0 & 100 & $1: 30$ & 50 & 10 & $1.80 \pm 0.02 \mathrm{~b}$ & 1.33 & 1.80 \\
\hline 27 & 1 & 1 & 1 & 1 & 100 & $1: 30$ & 75 & 15 & $1.86 \pm 0.05 b$ & 1.95 & 1.86 \\
\hline
\end{tabular}

a TPC: total phenolic content, expressed as mg gallic acid equivalents per gram of dry matter. Data are reported as mean \pm standard deviation. Each run was replicated four times $(n=4)$. Different letters in the Experimental column indicate significant differences in the mean $(p<0.05)$. 
A second-order polynomial equation was used to express the predicted response as a function of the four independent parameters, as follows:

$$
Y=\beta_{0}+\sum_{i=1}^{4} \beta_{i} X_{i}+\sum_{i=1}^{4} \beta_{i i} X_{i i}^{2}+\sum_{i j, i<j} \beta_{i j} X_{i} X_{j}+e_{i}
$$

where $Y=$ total phenolic content (TPC); $X_{1}=$ solvent composition $(\%) ; X_{2}=$ solid-to-solvent ratio; $\mathrm{X}_{3}=$ temperature $\left({ }^{\circ} \mathrm{C}\right) ; \mathrm{X}_{4}=$ extraction time $(\mathrm{min}) ; \beta_{0}=$ intercept; $\beta_{\mathrm{i}}, \beta_{\mathrm{ii}}, \beta_{\mathrm{ij}}=$ linear, quadratic and interactive coefficients, respectively; $\mathrm{e}_{\mathrm{i}}=$ error term.

\subsection{Statistical Analysis}

The experimental design, data analysis and optimization procedure were carried out by Statistica statistical package software (Stat Soft Inc., Tulsa, OK, USA). Data were reported as means \pm standard deviation (SD). The statistical significance of the main effects, the interactions and the quadratic terms, regression coefficients and model fitting were evaluated by analysis of variance (ANOVA). Model adequacy was checked by the coefficient of determination $\mathrm{R}^{2}$ and adjusted coefficient of determination $\mathrm{R}_{\mathrm{adj}}{ }^{2}$. From the obtained regression models, three-dimensional response surfaces and contour plots were drawn to understand the relationships between the response and experimental levels of each factor.

\subsection{Authentication of Optimized Conditions}

Once the mathematical model was obtained, the multi-response optimization using desirability function [16] was used to maximize the TPC of the KP extract.

It is a procedure which is used to specify the relationship between predicted responses on a dependent variable and the desirability of the responses, called the desirability function. Overall desirability (D) is computed as the geometric mean of the individual desirability $\mathrm{d}_{\mathrm{i}}$, as follows:

$$
\mathrm{D}=\left(\prod_{\mathrm{i}=1}^{n} \mathrm{~d}_{\mathrm{i}}\right)^{\frac{1}{n}}
$$

where $n=$ total number of responses in the study. Desirability values range from 0.0 for undesirable to 1.0 for a very desirable response. Therefore, a simultaneous optimization of several response variables consists of selecting the levels of the predictor variables that maximize the overall desirability of the responses on the dependent variables.

Once the extraction conditions to obtain the maximum yield of phenolic compounds were optimized, new measurements were carried out in triplicate. The goodness of the obtained predictive models was determined by the comparison between the new experimental and predicted values.

\subsection{Artificial Neural Network Modelling}

An artificial neural network is composed of interconnected neurons laid at different levels. Neurons of the first level receive the input values, weighted individually, from external sources. The number of artificial neurons or nodes equals the size of the input vector. All the input nodes send a signal to each hidden node as a weighted sum and are then subjected to the activation function. The same process also applied for the signal from the hidden layer to the output layer. Neurons of the last level provide the final output values calculated by the network.

The ANN is potentially more accurate by including all of the experimental data; this provides the modelling of complex nonlinear relationships. Herein, a typical feed-forward architecture of ANN, also known as multilayered perceptron (MLP), was employed to build a predictive model for the TPC of KP extract. 
In this study, the ANN scheme is defined by an input layer (independent variables: temperature, extraction time, solvent composition and solid-to-solvent ratio), a number of hidden layers and an output layer (TPC), as drawn in Figure 1. The activation functions in hidden and output neurons are exponential and hyperbolic tangent functions, respectively. The ANN model is shown below:

$$
\mathrm{TPC}=\left[\sum_{1}^{n} \mathrm{w}_{2 \mathrm{i}} \tanh \left(\sum_{\mathrm{j}}^{4} \mathrm{w}_{1 \mathrm{ij}} \mathrm{x}_{\mathrm{j}}+\mathrm{b}_{1 \mathrm{i}}\right)\right]+\mathrm{b}_{2}
$$

where $x_{j}$ is the four input independent variables (temperature, extraction time, solvent composition and solid-to-solvent ratio); $\mathrm{n}$ is the number of neurons which were optimized at 7 for one hidden layer; $\mathrm{w}_{1}$ is the weight of the hidden layer; $\mathrm{w}_{2}$ is the weight of the output layer; $\mathrm{b}_{1}$ is the bias of the hidden layer, and $b_{2}$ is the bias of the output layer.

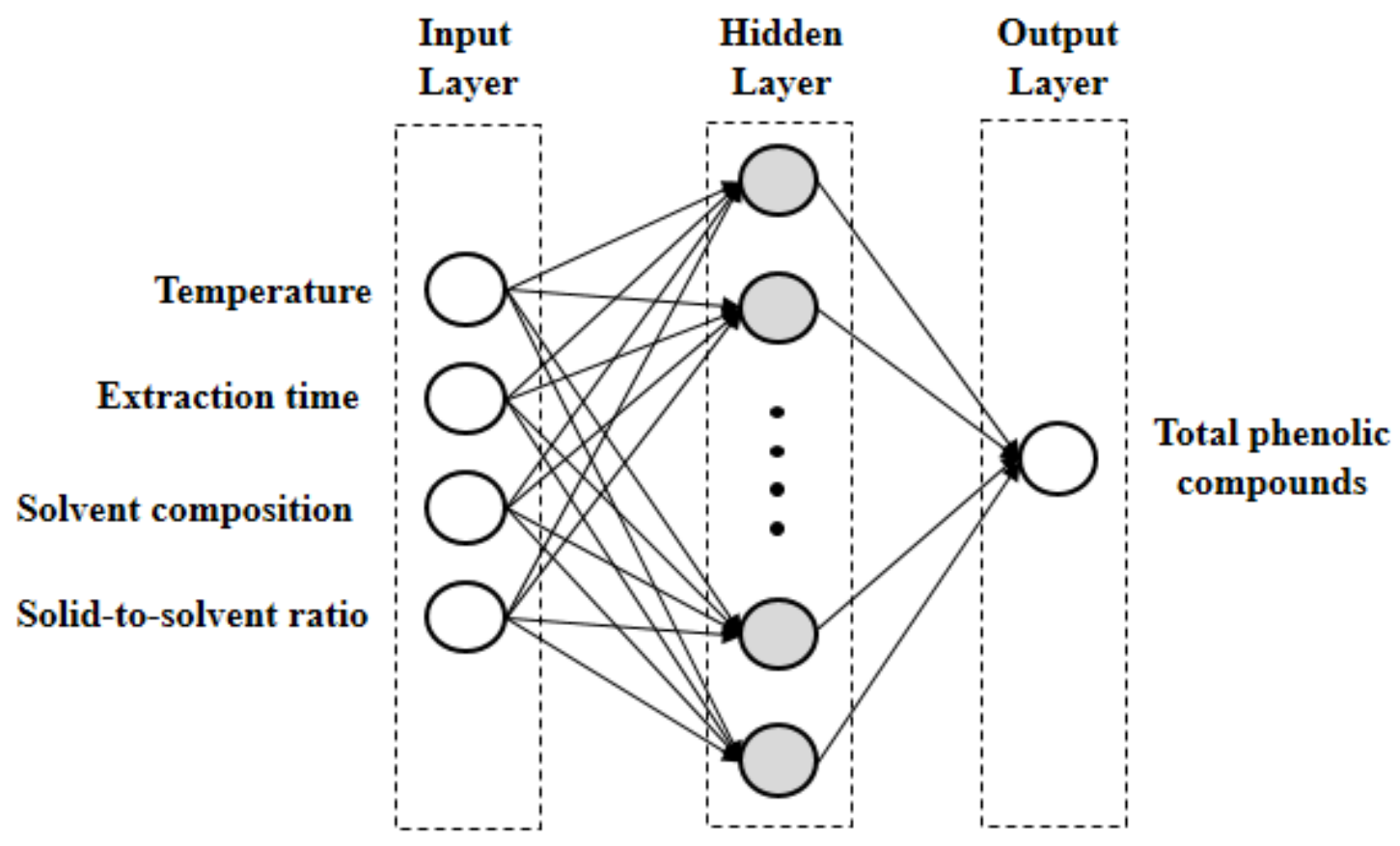

Figure 1. Artificial neural network architecture.

The experimental data obtained from the fractional factorial matrix were divided randomly into three sets: a training set (60\% of data points) to estimate model parameters, a cross-validation set $(20 \%)$ to indicate possible over-learning and over-parameterization, and testing set $(20 \%)$ to check the model performance.

\subsection{Microwave-Assisted Extraction of Total Polyphenolic Compounds from Kiwifruit Pomace}

Freeze-dried kiwi juice pomace $(1 \mathrm{~g})$ was extracted according to the experimental conditions shown in Table 1, using a Microwave Accelerated Reaction System (MARS 5 model; CEM Corporation, Matthews, NC, USA). The extraction was performed following the experimental design (Table 1) at a microwave power of $400 \mathrm{~W}$ and pressure of $350 \mathrm{psi}$. Once extracted, samples were cooled down at room temperature, then centrifuged at $6792 \times \mathrm{g}$, for $15 \mathrm{~min}$ at $4{ }^{\circ} \mathrm{C}$ and the supernatants immediately analyzed. Each experiment was carried out in triplicate according to the fractional factorial matrix (Table 1), and the average value was taken for the data analysis and the modelling of the extraction process. All further analytical determinations were performed in triple on two independent extraction replicates. 


\subsection{Phytochemical Analysis}

The total polyphenol content (TPC) and flavan-3-ol content (FLC) of KP extracts were determined according to Carbone et al. [17]. Data were expressed as mg gallic acid equivalents (GAEs) and mg catechin equivalents (CAEs) per g of dry weight pomace for TPC and FLC, respectively. Ascorbic acid content (AAC) was determined according Ciccoritti et al. [18]. AAC was calculated using an ascorbic acid calibration curve and results were expressed as mg of ascorbic acid (AA) per $100 \mathrm{~g}$ of dry weight pomace. KP chlorophyll extraction and determination was carried on according to Soquetta et al. [9] without modifications. Data were expressed as mg per $100 \mathrm{~g}$ of dry weight pomace. The antiradical potential of KP extracts was evaluated with two different in vitro assays ( $\mathrm{DPPH}^{\bullet}$ and $\mathrm{ABTS}^{\bullet+}$ ) according to Ciccoritti et al. [18]. The antiradical capacity, in both assays, was expressed in terms of $\mathrm{EC}_{50}$ (sample concentration capable of reducing the radical by $50 \%$; [17]).

All determinations were performed in triplicate.

\section{Results and Discussion}

\subsection{Fractional Factorial Design and Analysis}

In the present study, a fractional factorial design was used to obtain a proper model for the optimization of MAE processes, with four variables tested at three levels. Experiments were carried out according to the experimental design matrix shown in Table 1 , in order to evaluate the optimal conditions and study the influence of process variables on the extraction of bioactive compounds from $\mathrm{KP}$. The observed results and predicted values are reported in the same table.

The total polyphenols (TPs) yield varied from 1.30 to $4.87 \mathrm{mg} \mathrm{GAE} \mathrm{g}^{-1} \mathrm{dw}$ (runs 23 and 3, respectively; Table 1). Overall, high TPC values were achieved at a temperature equal to $75^{\circ} \mathrm{C}$, regardless of the levels of the other process factors (Table 1). Under high temperatures, plant tissues are softened, and the phenol-protein and phenol-polysaccharide interactions weaken; as a result, phenolic compounds can be easily extracted in the solvent [19]. However, a right compromise must be chosen as high temperatures may cause the oxidation and degradation of the phytochemical compounds, as well as the co-extraction of undesirable compounds [19].

Fitting of the data to various models (e.g., linear, quadratic, etc.) was performed to acquire the regression equations (data not shown). Among tested models, the second-order polynomial one was highly significant $(p<0.0001)$, describing satisfactorily the experimental data as shown by its coefficient of determination $R^{2}(0.90)$ and adjusted $R_{a d j}{ }^{2}(0.89)$. Hence, it was chosen for further analysis of the data. The equation generated in coded factors is shown below:

$$
\begin{array}{rl}
\mathrm{TPC}_{\mathrm{RSM}}=4 & 4.5200+0.0476 \mathrm{X}_{1}+0.0231 \mathrm{X}_{2}-0.0301 \mathrm{X}_{3}-0.1945 \mathrm{X}_{4} \\
& -0.0002 \mathrm{X}_{1} \mathrm{X}_{2}+0.0001 \mathrm{X}_{1} \mathrm{X}_{3}+0.0001 \mathrm{X}_{1} \mathrm{X}_{4} \\
& -0.0013 \mathrm{X}_{2} \mathrm{X}_{3}-0.0005 \mathrm{X}_{2} \mathrm{X}_{4}+0.0011 \mathrm{X}_{3} \mathrm{X}_{4} \\
& -0.0007 \mathrm{X}_{1}^{2}+0.0012 \mathrm{X}_{2}^{2}+0.0005 \mathrm{X}_{3}^{2}+0.0073 \mathrm{X}_{4}^{2}
\end{array}
$$

where: $X_{1}, X_{2}, X_{3}$ and $X_{4}$ are the coded variables for solvent composition, solid-to-solvent ratio, temperature, and extraction time, respectively. The second-order polynomial regression equation showed an empirical relationship between the response (TPC) and input variables, and the magnitude and sign of the coefficients for intercept, linear, quadratic and interaction effects pointed out the influence of each factor. To ensure the adequacy and fitness of the model, an analysis of variance (ANOVA) was applied, providing the linear, quadratic and two-factor interaction effects of ethanol concentration $\left(X_{1}\right)$, solid-to-solvent ratio $\left(X_{2}\right)$, extraction temperature $\left(X_{3}\right)$, and extraction time $\left(X_{4}\right)$ on TPC. The statistical significance of the model, the independent variable and their possible interactions were evaluated by means of the $p$ value. ANOVA results are shown in Table 2. 
Table 2. ANOVA for the second-order polynomial equation for microwave-assisted extraction of total phenolic compounds (TPC).

\begin{tabular}{|c|c|c|c|c|c|c|}
\hline & $\begin{array}{l}\text { Sum of } \\
\text { Square }\end{array}$ & $\begin{array}{l}\text { Degree of } \\
\text { Freedom }\end{array}$ & $\begin{array}{l}\text { Mean } \\
\text { Square }\end{array}$ & F-Value & $p$-Value & Significance \\
\hline$X_{1}$ & 48.5769 & 1 & 48.5769 & 317.3026 & $<0.0001$ & $* * *$ \\
\hline$x_{2}$ & 0.6476 & 1 & 0.6476 & 4.2502 & 0.0425 & $*$ \\
\hline$x_{3}$ & 2.1135 & 1 & 2.1135 & 13.8055 & 0.0003 & $* * *$ \\
\hline$X_{4}$ & 0.0219 & 1 & 0.0219 & 0.1429 & 0.7062 & ns \\
\hline$x_{1} x_{2}$ & 0.3115 & 1 & 0.3115 & 2.0349 & 0.1570 & ns \\
\hline$x_{1} x_{3}$ & 0.8212 & 1 & 0.8212 & 5.3643 & 0.0227 & * \\
\hline$x_{1} x_{4}$ & 0.0221 & 1 & 0.0221 & 0.1442 & 0.7050 & ns \\
\hline$x_{2} x_{3}$ & 4.0416 & 1 & 4.0416 & 26.3994 & $<0.0001$ & $* * *$ \\
\hline$x_{2} x_{4}$ & 0.0185 & 1 & 0.0185 & 0.1211 & 0.7286 & ns \\
\hline$x_{3} x_{4}$ & 0.7193 & 1 & 0.7193 & 4.6984 & 0.0327 & * \\
\hline $\mathrm{X}_{1}^{2}$ & 68.9947 & 1 & 68.9947 & 450.6707 & $<0.0001$ & $* * *$ \\
\hline$x_{2}^{2}$ & 0.3384 & 1 & 0.3384 & 2.2103 & 0.1404 & ns \\
\hline$x_{3}^{2}$ & 2.0114 & 1 & 2.0114 & 13.1383 & 0.0005 & $* * *$ \\
\hline$x_{4}^{2}$ & 0.8040 & 1 & 0.8040 & 5.2519 & 0.0242 & $*$ \\
\hline Residual & 14.3908 & 94 & 0.1531 & & & \\
\hline Total SS & 144.1879 & 108 & & & & \\
\hline $\mathrm{R}^{2}$ & 0.900 & & & & & \\
\hline $\mathrm{R}_{\mathrm{adj}}{ }^{2}$ & 0.885 & & & & & \\
\hline
\end{tabular}

$\mathrm{X}_{1}$ : solvent composition $(\%) ; \mathrm{X}_{2}$ : solid-to-solvent ratio; $\mathrm{X}_{3}$ : temperature $\left({ }^{\circ} \mathrm{C}\right) ; \mathrm{X}_{4}$ : extraction time $(\mathrm{min}) .{ }^{*}$ and ${ }^{* * *}$ indicate significance at $p<0.05$ and 0.001 , respectively; ns indicates not significant.

Among the independent variables investigated, only the extraction time $\left(\mathrm{X}_{4}\right)$ had no significant linear effect on the extraction yield of TPs from KP extracts $(p>0.05$, Table 2). Besides, solvent composition $\left(\mathrm{X}_{1}\right)$ displayed a significant $(p<0.001)$ linear effect on the yield of TPs and a significant $(p<0.001)$ negative quadratic effect. The linear and quadratic terms of temperature $\left(X_{3}\right)$ were also found highly significant $(p<0.0001)$, whereas only the linear term for the solid-to-solvent ratio $\left(X_{2}\right)$ had a significant result $(p<0.05)$.

\subsection{Response Optimization Using the Desirability Function Approach}

To visualize the influence of the independent variables on the TP extraction from KP, the desirability surface and the contour plots were generated.

Model optimization was carried out using Derringer's desirability function (Figure 2), which allows the analyst to find the experimental conditions (factor levels) to reach, simultaneously, the optimal value for all the investigated variables. Profiles of the desirability function for each parameter are drawn in Figure 2. The desirability function graph shows the desirability of the response (which can range from 0.0 for undesirable up to 1.0 for very desirable) across the observed range of each class. Therefore, the predicted optimal values for the independent variables were as follows: $X_{1}=50$; $X_{2}=1: 15 ; X_{3}=75 ; X_{4}=15$ (Figure 2 ). 
$\mathrm{X} 1$
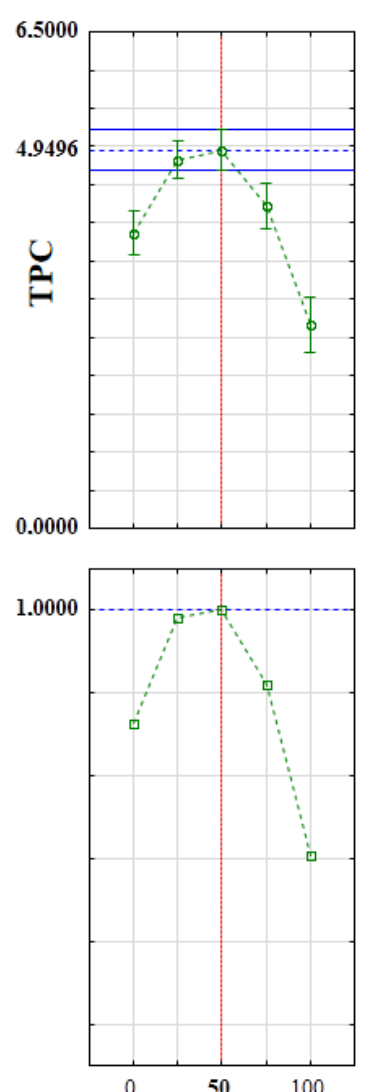

X2
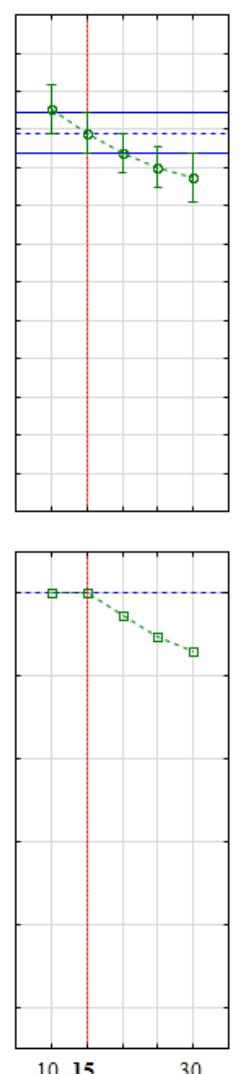

X3
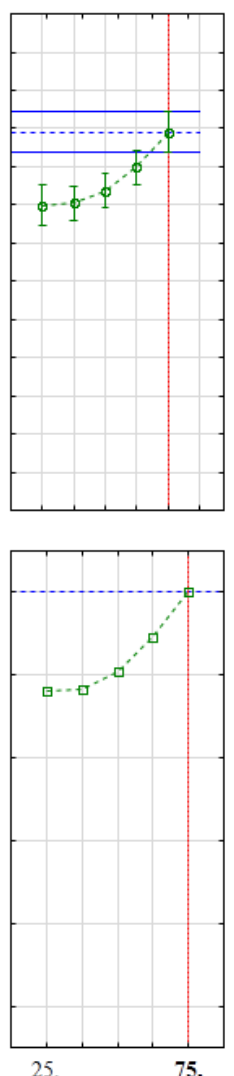

$\mathrm{X} 4$
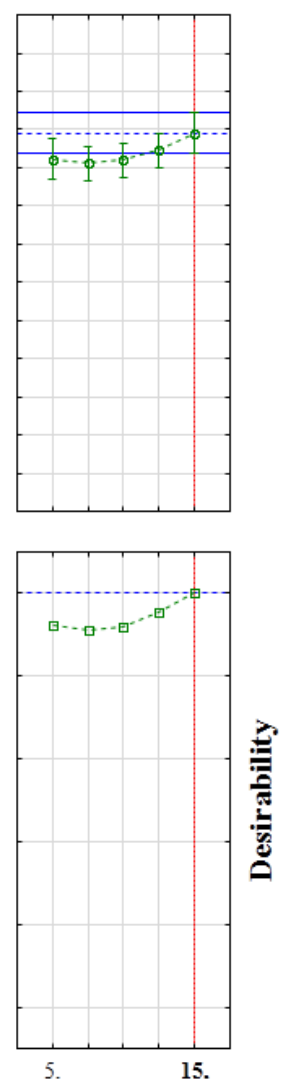

Desirability

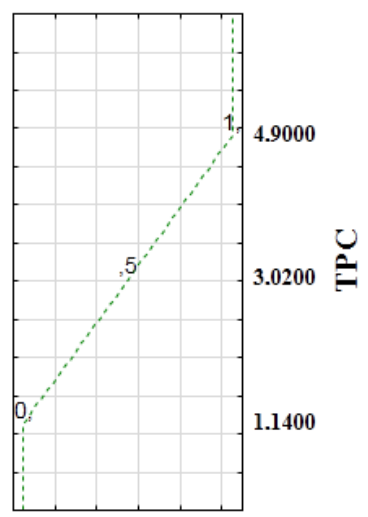

Figure 2. Profiles for predicted values and desirability function for the extraction of total phenolic content from kiwifruit pomace. Red lines indicate optimized values for each process parameter $\left(\mathrm{X}_{1}=\right.$ solvent composition, $\mathrm{X}_{2}=$ solid-to-solvent ratio, $\mathrm{X}_{3}=$ temperature, $\mathrm{X}_{4}=$ extraction time).

The effects of analyzed parameters on TPC are shown in 3D-response surface plots (Figure 3A-F).

These contour plots are helpful for interpreting the effects on the overall response desirability of different combinations of levels of each pair of independent variables, with the remaining independent variables being held constant at their current values. The plots revealed not only the values that lead to the optimal conditions, but also the interactions between variables. An elliptical profile of the bidimensional contour plot means high interactions between the parameters considered, whereas a circular contour plot denotes negligible interactions [20]. In the present study, no interactive effect of the solvent composition (\%) and solid-to-solvent ratio was found (Figure 3A). The yield of TPs increased with the increase in solvent composition from $0 \%$ to the intermediate level; after this, it gradually declined. This trend is confirmed by the literature data reporting that the TP yield increases up to a certain point then starts to decrease when $0-100 \%$ ethanol was used as the extraction solvent [21]. In the present study, we used ethanol as a food grade solvent in order to perform a completely green approach to the exploitation of kiwi juice pomace. According to Spigno et al. [22], the mixtures between water and alcohols proved to be more efficient in the extraction of phenolic compounds than the single-component solvent system. However, in the present study, this parameter showed a low impact on the TP yield although the desirability function showed slightly higher values at a lower solid-to-solvent ratio, which may be due to an increase in the surface contact of KP with the solvent leading to higher yields. Similar results were found by Bhuyan et al. [23]. 


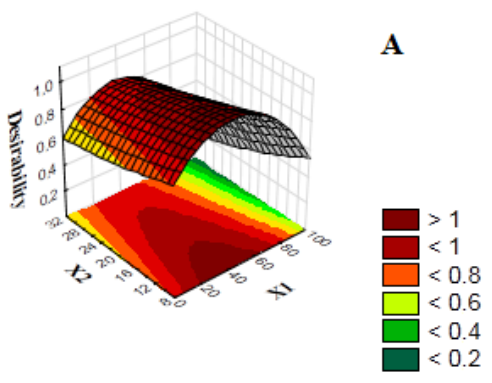

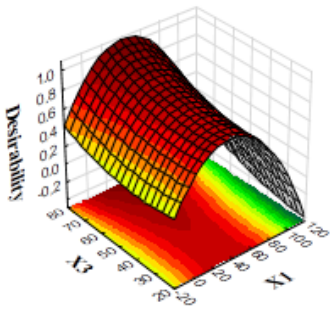
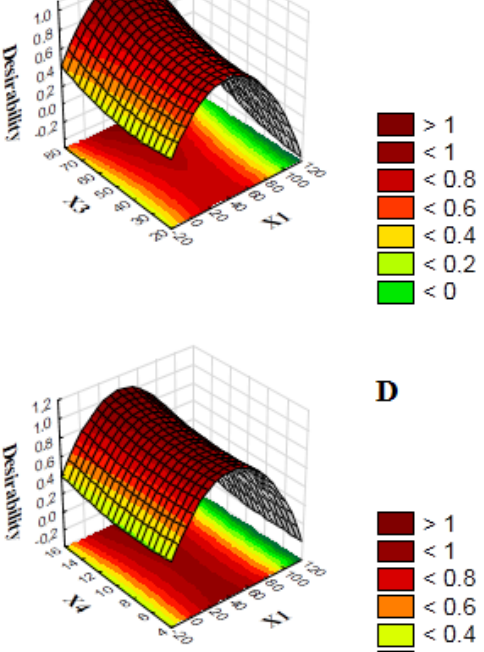

D

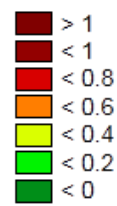

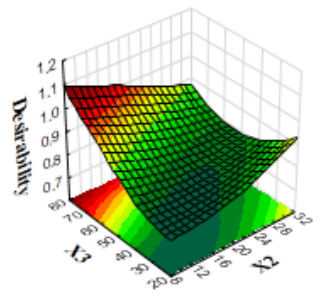

C

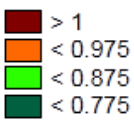

$\mathbf{E}$
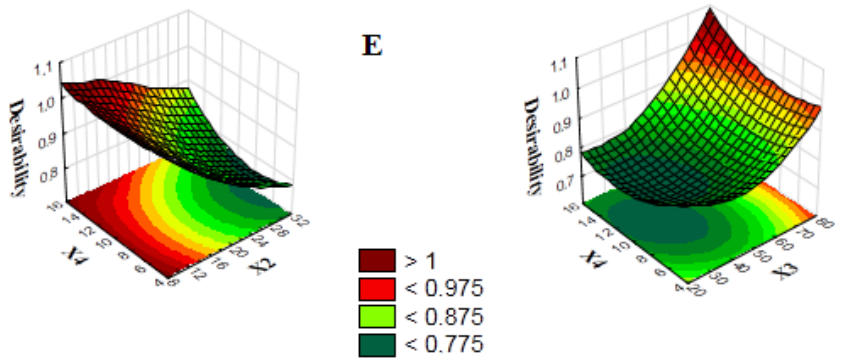

F $>1$ $<0.95$ $<0.85$

Figure 3. Response surface and contour plots of kiwifruit pomace extracts as a function of (A) $X_{1}=$ solvent composition and $X_{2}=$ solid-to-solvent ratio; (B) $X_{1}=$ solvent composition and $\mathrm{X}_{3}=$ temperature; (C) $\mathrm{X}_{2}=$ solid-to-solvent ratio and $\mathrm{X}_{3}=$ temperature; (D) $\mathrm{X}_{1}=$ solvent composition and $\mathrm{X}_{4}=$ extraction time; $(\mathrm{E}) \mathrm{X}_{2}=$ solid-to-solvent ratio and $\mathrm{X}_{4}=$ extraction time; $(\mathrm{F}) \mathrm{X}_{3}=$ temperature and $\mathrm{X}_{4}=$ extraction time.

Figure 3B shows the contour plot of solvent composition and extraction temperature on the TP extraction yield. As shown in the figure, the TP yield increases as the temperature increases, with the predicted maximum obtained at $75^{\circ} \mathrm{C}$ according to the optimized extraction results. It is well known that the increase in temperature promotes the extraction by improving the rate of release of phytocompounds into the solvent (i.e., diffusion coefficient), also in view of the higher dissociation of polyphenols linked with the membrane. As a result, an increase in TPC was observed at higher values of this variable. However, this cannot be increased indefinitely because higher temperatures could damage the phenolic compounds and cause a decrease in the extraction yield due to the occurrence of degradative mechanisms such as oxidative phenomena and the thermal degradation of thermolabile compounds [21].

Figure $3 \mathrm{C}$ highlights a strong interaction between the extraction temperature and solid-to-solvent ratio: by increasing the temperature up to $75{ }^{\circ} \mathrm{C}$ and decreasing the solid-to-solvent ratio to $1: 10$ the maximum desirability was obtained. On the other hand, decreasing temperatures to $25^{\circ} \mathrm{C}$ and increasing the solid-to-solvent ratio to 1:30 resulted in a minimal TP yield. These results are justified by the fact that the driving force during mass transfer is the concentration gradient between the solid and the bulk of the liquid, which is higher when a lower solid-to-solvent ratio $(\mathrm{S} / \mathrm{L})$ is used. Lower $\mathrm{S} / \mathrm{L}$ values promote an increase in the surface contact of the plant matrix with the solvent, with a consequent increase in extraction yields, which will be positively influenced by an increase in the temperature of the reaction medium due to the greater diffusivity of the solvent within the solid matrix. 
As it concerns the relationship between solvent composition and extraction time (Figure 3D), the desirability could reach a peak value at $15 \mathrm{~min}$ and $40-50 \%$ solvent composition. Longer extraction times reflect longer contact times between the plant matrix and the extraction medium that allow the release of phenols retained in the cell walls, which in turn is greater with a higher extraction temperature.

Considering the combined effect of the extraction time and solid-to-solvent ratio, the response surface plot suggests that the highest TPC value can be obtained with the lowest solid-to-solvent ratio value (Figure $3 \mathrm{E}$ ), whereas the time factor appeared almost irrelevant, indicating the absence of interaction between these two parameters $(p>0.05$, Table 2). Similar results were also observed by Bhuyan et al. [23].

Finally, increasing the extraction time at $75{ }^{\circ} \mathrm{C}$ enhanced the desirability score significantly (Figure 3F). At the same time, the latter decreased when the two factors decreased, although the phenomenon is more contained over a shorter extraction time.

Using the optimal values of the operative parameters found by the desirability function (Figure 2), a MAE experimental trial was carried out, leading to a TP yield of $4.79 \pm 0.13 \mathrm{mg} \mathrm{GAE} \mathrm{g}^{-1}$. Besides, the predicted TP yield obtained by the developed RMS model was $4.90 \mathrm{mg} \mathrm{GAE} \mathrm{g}^{-1}$, indicating a good agreement between experimental and predicted values, which confirmed the correctness of the developed model.

\subsection{ANN Modelling}

In the present study, an artificial neural network (ANN) was applied to the experimental data with the aim of improving the model performance.

The optimal ANN configuration for TPC was developed considering four neurons in the input layer, corresponding to the four independent variables (solvent composition, solid-to-solvent ratio, temperature, and extraction time); seven hidden layers, which ensured low training error and no underfitting or overfitting, according to the technique described by Piotrowsky and Napiorkowski [24]; one output layer, corresponding to the predicted TPC (Figure 1). The feed-forward multilayered perceptron ANN was trained using a back-propagation method, based on Levenberg-Marquardt algorithm [25]. The parameters of the ANN model are shown in Table S1. The predicted ANN values of TPCs are shown in Table 2 and the correlation between the predicted and experimental values in Figure 4. Obtained results show a high goodness of fit, with an ANN coefficient of determination $\mathrm{R}^{2}$ equal to 0.99 . The ANN predicted values for TPC was found to be $4.95 \mathrm{mg} \mathrm{GAE} \mathrm{g}^{-1}$.
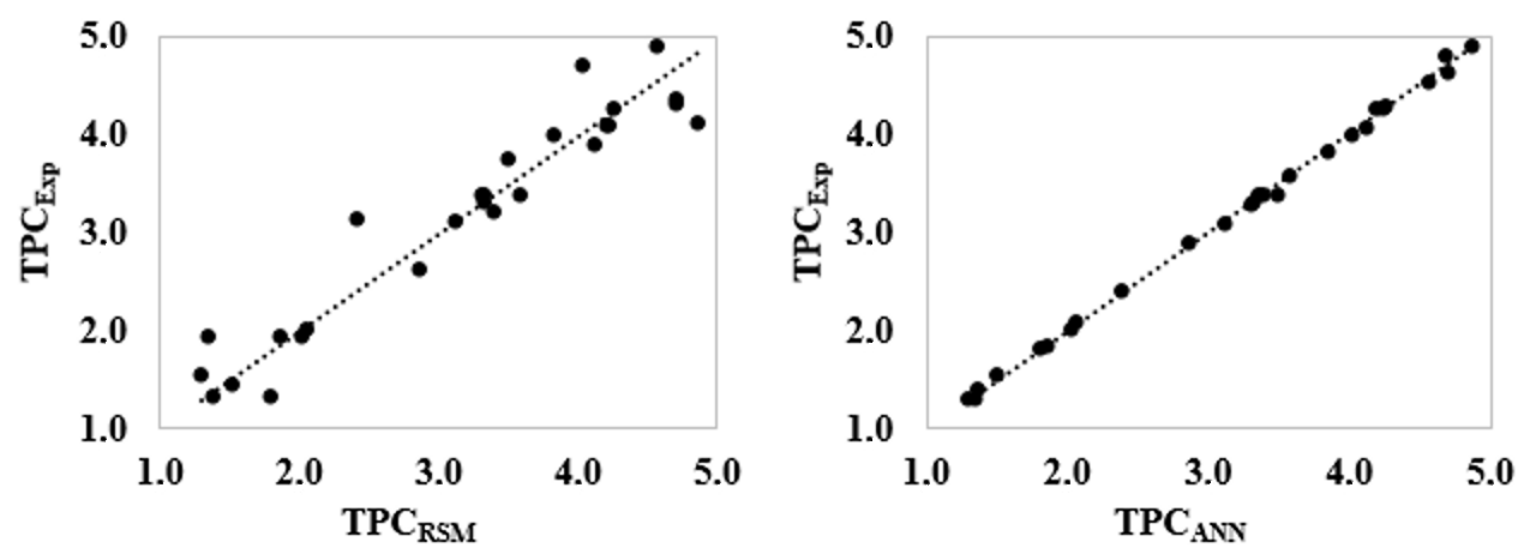

Figure 4. Comparison of the experimental total phenolic content $\left(\mathrm{TCP}_{\mathrm{Exp}}\right)$ and those predicted by response surface methodology $\left(\mathrm{TPC}_{\mathrm{RSM}}\right)$ and artificial neural network $\left(\mathrm{TPC}_{\mathrm{ANN}}\right)$.

\subsection{A Comparison between RSM and ANN Statistical Models}

Figure 4 shows the correlation between the observed total phenolic contents ( $\mathrm{TPC}_{\exp }$ ) and those predicted by response surface methodology $\left(\mathrm{TPC}_{\mathrm{RSM}}\right)$ and by $\mathrm{ANN}$ technique $\left(\mathrm{TPC}_{\mathrm{ANN}}\right)$. In both cases, 
predicted values were found to be linear with the experimental ones, with a coefficient of determination $\left(R^{2}\right)$ equal to 0.90 and 0.99 , respectively, pointing out a better data fitting by ANN. It can be attributed to the ANN capability to be distribution-independent and to approximate the nonlinearity of the system, while the RSM generally considers only a second-order polynomial. However, the RSM has the advantage of giving an idea of the significance of each factor considered for building the predictive model and their interactions.

\subsection{Preliminary Characterization of Optimized KP Extract}

The optimized KP extract was preliminary characterized for its bioactive compound content and radical scavenging power (Table 3). The TPC of the optimized KP extract was $4.79 \pm 0.13 \mathrm{mg}$ $\mathrm{GAE} \mathrm{g}^{-1}$, while the FLC was $1.38 \pm 0.01 \mathrm{mg} \mathrm{CAT}^{-1}$. These results are higher than those reported by Soquetta et al. [9] for ripe kiwifruit bagasse flour (FBM samples, data expressed as $\mathrm{mg}^{100 \mathrm{~g}^{-1} \text { of }}$ flour), probably due to the different kiwi variety and extraction method employed herein. Moreover, the optimized MAE of kiwifruit pomace gave a double yield in vitamin $C$ compared to that reported by the same authors. Chlorophylls in kiwifruit (A. deliciosa) are one of the main pigments that contribute to the characteristic bright green color of its flesh [26]. Their consumption has been associated with protective effects against several degenerative disorders such as atherosclerosis, osteoporosis, cataracts, neurodegenerative diseases, and oxidative stress [27]. In the present study, an optimized MAE extraction of the KP yielded a total chlorophyll content that was about three-fold the total chlorophyll content found by Soquetta et al. [9], for ripe kiwifruit bagasse flour.

Table 3. Phytochemical characterization of optimized kiwi juice pomace (mean \pm SD).

\begin{tabular}{ccc}
\hline Parameter & Experimental Values & Literature Values $^{\mathbf{a}}$ \\
\hline TPC & $4.8 \pm 0.1$ & $<2.0$ \\
FLC & $1.38 \pm 0.01$ & $<1.0$ \\
AAC & $120.6 \pm 0.5$ & 59.80 \\
TCC & $5.9 \pm 0.1$ & 2.02 \\
AC & $5.49 \pm 0.02$ & $39.45^{\mathrm{b}}$ \\
AC & $560 \pm 1$ & n.d
\end{tabular}

\footnotetext{
a Soquetta et al., 2016. ${ }^{\mathrm{b}}$ Data are expressed as $\mathrm{mg} \mathrm{ml}^{-1}$. TPC: total polyphenol content (mg GAE g ${ }^{-1}$ ); FLC:

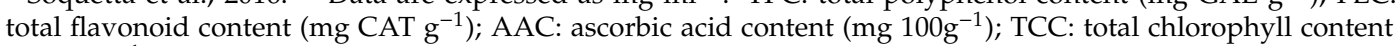
$\left(\mathrm{mg} 100 \mathrm{~g}^{-1}\right)$; $\mathrm{AC}_{\mathrm{DPPH}}$ : antiradical capacity (DPPH in vitro test; data are expressed in terms of $\mathrm{EC}_{50}$ as $\mathrm{mg}$ ); $\mathrm{AC}_{\mathrm{ABTS}}$ : antiradical capacity $\left(2,2^{\prime}\right.$-azino-bis(3-ethylbenzthiazoline-6-sulphonic acid) (ABTS) in vitro test; data are expressed in terms of $\mathrm{EC}_{50}$ as $\left.\mu \mathrm{g}\right)$.
}

In order to evaluate the capacity of KP bioactive components to scavenge free radicals, we used both DPPH and ABTS assays as they are easy to implement and produce the most reproducible results [28]. ABTS ${ }^{+\cdot}$ can be solubilized in both aqueous and organic media, in which the antioxidant activity can be measured due to the hydrophilic and lipophilic nature of the compounds in samples [29]. In contrast, $\mathrm{DPPH}^{\circ}$ can only be dissolved in organic media (i.e., methanol), taking into account mainly the lipophilic antioxidants in the extract to be analyzed. The results, in both cases, are expressed in an indirect way, measuring the quantity of antioxidant necessary to reduce the initial radical concentration by $50 \%$, which is a value generally defined as $\mathrm{EC}_{50}$ : the higher the antioxidant capacity, the lower this value is.

The obtained results pointed out that the optimized KP extract was almost 10 times more effective in scavenging the radical ABTS than the DPPH, which was consistent with the high content of hydrophilic bioactive compounds extracted from KP (i.e., vitamin C). These findings also agree with the results of Zhu et al. [8], who reported, among total polyphenols extracted from kiwi pomace, large amounts of phenolic acids, which contribute to the higher antioxidant potential when an ABTS assay is employed. 


\section{Conclusions}

In this study, for the first time, chemometric techniques were used to optimize the microwave-assisted extraction process of natural antioxidants from kiwi juice pomace. A fractional factorial design and desirability profile were used for the optimization of the process variables (temperature, extraction time, solvent composition and solid-to-solvent ratio) and to investigate their interactions. Results highlighted that the solvent composition and, to a lesser extent, temperature and solid-to-solvent ratio, significantly affected all responses, whereas the extraction time did not influence the TPC extraction yield linearly. The optimal conditions for the extraction of TPC from kiwi juice pomace were found: solvent composition $=50$; solid-to-solvent ratio $=1: 15$; temperature $=75^{\circ} \mathrm{C}$; extraction time $=15 \mathrm{~min}$. Response surface methodology and an artificial neural network were used to develop predictive models for the simulation of the extraction process. Both models provided satisfactory results, but the ANN model demonstrated a higher predictive capability than the RMS one. A preliminary characterization of the optimally obtained extract revealed higher values of investigated phytochemicals, and antiradical potential compared to those reported in the literature for kiwi juice bagasse, underling the high efficiency of this green extraction technique for the recovery and valorization of kiwi juice pomace. Natural antioxidants from KP may represent a considerable economic benefit for farmers and kiwifruit chain stakeholders, as, if properly recovered, they could be used for the design of new functional foods, as well as natural dyes and food flavoring agents or in substitution of synthetic antioxidants.

Supplementary Materials: The following are available online at http://www.mdpi.com/2077-0472/10/10/435/s1, Table S1: Parameters of the ANN model.

Author Contributions: Conceptualization, K.C.; investigation, R.I. and K.C.; methodology, K.C. and T.A.; resources, K.C.; supervision, K.C. and T.A.; validation, K.C. and T.A.; writing-review and editing, K.C. and T.A. All authors have read and agreed to the published version of the manuscript.

Funding: This research received no external funding.

Conflicts of Interest: The authors declare no conflict of interest.

\section{References}

1. Huang, H.W.; Ferguson, A.R. Actinidia in China: Natural diversity, phylogeographical evolution, interspecific gene flow and kiwifruit cultivar improvement. Acta Hortic. 2007, 753, 31-40. [CrossRef]

2. Guroo, I.; Wani, S.A.; Wani, S.M.; Ahmad, M.; Mir, S.A.; Masoodi, F.A. A review of production and processing of kiwifruit. J. Food Proc. Technol. 2017, 8, 8.

3. Faostat. Available online: http://faostat3.fao.org/browse/Q/QC/E (accessed on 30 December 2018).

4. Drummond, L. The composition and nutritional value of kiwifruit. In Advances in Food and Nutrition Research; Academic Press: Cambridge, MA, USA, 2013; pp. 33-57.

5. Padmanabhan, P.; Paliyath, G. Kiwifruit. In Encyclopedia of Food and Health; Academic Press: Oxford, UK, 2016; pp. 490-494. [CrossRef]

6. Martin-Cabrejas, M.A.; Esteban, R.M.; Lopez-Andreu, F..; Waldron, K.; Selvendran, R. Dietary fiber content of pear and kiwi pomaces. J. Agric. Food Chem. 1995, 43, 662-666. [CrossRef]

7. Carbone, K.; Garrigos, M.C.; Jimenez, A. Polyphenols: From wastes to high added value bio-products. In Frontiers in Natural Product Chemistry; Rahman, A., Ed.; Bentham Books: Sharjah, UAE, 2016; Volume 2, pp. 115-178.

8. Zhu, M.; Huang, Y.; Wang, Y.; Shi, T.; Zhang, L.; Chen, Y.; Xie, M. Comparison of (poly) phenolic compounds and antioxidant properties of pomace extracts from kiwi and grape juice. Food Chem. 2019, 271, 425-432. [CrossRef] [PubMed]

9. Soquetta, M.B.; Stefanello, F.S.; da Mota Huerta, K.; Monteiro, S.S.; da Rosa, C.S.; Terra, N.N. Characterization of physiochemical and microbiological properties, and bioactive compounds, of flour made from the skin and bagasse of kiwi fruit (Actinidia deliciosa). Food Chem. 2016, 199, 471-478. [CrossRef] [PubMed]

10. Ameer, K.; Shahbaz, H.M.; Kwon, J.H. Green Extraction Methods for Polyphenols from Plant Matrices and Their Byproducts: A Review. Compr. Rev. Food Sci. Food Saf. 2017, 16, 295-315. [CrossRef] 
11. Sarve, A.; Sonawane, S.S.; Varma, M.N. Ultrasound assisted biodiesel production from sesame (Sesamum indicum L.) oil using barium hydroxide as a heterogeneous catalyst: Comparative assessment of prediction abilities between response surface methodology (RSM) and artificial neural network (ANN). Ultrason. Sonochem. 2015, 26, 218-228. [CrossRef]

12. Witek-Krowiak, A.; Chojnacka, K.; Podstawczyk, D.; Dawiec, A.; Pokomeda, K. Application of response surface methodology and artificial neural network methods in modelling and optimization of biosorption process. Bioresour. Technol. 2014, 160, 150-160. [CrossRef]

13. Zheng, N.; Chen, F.; Wang, Z.; Lin, J. Modelling and optimization of artificial neural network and response surface methodology in ultra-high-pressure extraction of Artemisia argyi Levl. et Vant and its antifungal activity. Food Anal. Methods 2013, 6, 421-431. [CrossRef]

14. Dahmoune, F.; Remini, H.; Dairi, S.; Aoun, O.; Moussi, K.; Bouaoudia-Madi, N.; Mouni, L. Ultrasound assisted extraction of phenolic compounds from P. lentiscus L. leaves: Comparative study of artificial neural network (ANN) versus degree of experiment for prediction ability of phenolic compounds recovery. Ind. Crops Prod. 2015, 77, 251-261. [CrossRef]

15. Dai, J.; Mumper, R.J. Plant phenolics: Extraction, analysis and their antioxidant and anticancer properties. Molecules 2010, 15, 7313-7352. [CrossRef] [PubMed]

16. Derringer, G.; Suich, R. Simultaneous optimization of several response variables. J. Qual. Technol. 1980, 12, 214-219. [CrossRef]

17. Carbone, K.; Giannini, B.; Picchi, V.; Lo Scalzo, R.; Cecchini, F. Phenolic composition and free radical scavenging activity of different apple varieties in relation to the cultivar, tissue type and storage. Food Chem. 2011, 127, 493-500. [CrossRef]

18. Ciccoritti, R.; Paliotta, M.; Centioni, L.; Mencarelli, F.; Carbone, K. The effect of genotype and drying condition on the bioactive compounds of sour cherry pomace. Eur. Food Res. Technol. 2017, 244, 635-645. [CrossRef]

19. Shi, J.; Yu, J.; Pohorly, J.; Young, J.C.; Bryan, M.; Wu, Y. Optimization of the extraction of polyphenols from grape seed meal by aqueous ethanol solution. J. Food Agric. Environ. 2003, 1, 42-47.

20. Liu, Y.; Wei, S.; Liao, M. Optimization of ultrasonic extraction of phenolic compounds from Euryale ferox seed shells using response surface methodology. Ind. Crops Prod. 2013, 49, 837-843. [CrossRef]

21. Yılmaz, M.; Karaaslan, M.; Vardin, H. Optimization of extraction parameters on the isolation of phenolic compounds from sour cherry (Prunus cerasus L.) pomace. J. Food Sci. Technol. 2015, 52, 2851-2859. [CrossRef]

22. Spigno, G.; Tramelli, L.; De Faveri, D.M. Effects of extraction time, temperature and solvent on concentration and antioxidant activity of grape marc phenolics. J. Food Eng. 2007, 81, 200-208. [CrossRef]

23. Bhuyan, D.J.; Van Vuong, Q.; Chalmers, A.C.; van Altena, I.A.; Bowyer, M.C.; Scarlett, C.J. Microwave-assisted extraction of Eucalyptus robusta leaf for the optimal yield of total phenolic compounds. Ind. Crops Prod. 2015, 69, 290-299. [CrossRef]

24. Piotrowski, A.P.; Napiorkowsk, J.J. A comparison of methods to avoid overfitting in neural networks training in the case of catchment runoff modelling. J. Hydrol. 2013, 476, 97-111. [CrossRef]

25. Marquardt, D.W. An Algorithm for Least-Squares Estimation of Nonlinear Parameters. J. Soc. Ind. Appl. Math. 1963, 11, 431-441. [CrossRef]

26. Nishiyama, I.; Fukuda, T.; Oota, T. Genotypic differences in chlorophyll, lutein, and $\beta$-carotene contents in the fruits of Actinidia species. J. Agric. Food. Chem. 2005, 53, 6403-6407. [CrossRef] [PubMed]

27. Ferruzzi, M.G.; Blakeslee, J. Digestion, absorption, and cancer preventative activity of dietary chlorophyll derivatives. Nutr. Res. 2007, 27, 1-12. [CrossRef]

28. Buenger, J.; Ackermann, H.; Jentzsch, A.; Mehling, A.; Pfitzner, I.; Reiffen, K.A.; Wollenweber, U. An interlaboratory comparison of methods used to assess antioxidant potentials. Int. J. Cosmet. Sci. 2006, 28, 135-146. [CrossRef] [PubMed]

29. Arnao, M.B. Some methodological problems in the determination of antioxidant activity using chromogen radicals: A practical case. Trends Food Sci. Technol. 2000, 11, 419-421. [CrossRef]

(C) 2020 by the authors. Licensee MDPI, Basel, Switzerland. This article is an open access article distributed under the terms and conditions of the Creative Commons Attribution (CC BY) license (http://creativecommons.org/licenses/by/4.0/). 